\title{
Anti-acetylcholine-receptor antibody concentrations after thymectomy in patients with myasthenia gravis
}

\section{Summary and conclusions}

Serum concentrations of anti-acetylcholine-receptor (anti-AChR) antibody were measured in patients with myasthenia gravis. In those patients undergoing thymectomy concentrations were measured before and after the operation to see whether there might be a connection between the thymus and antibody production. We found no correlation between antibody concentration and either thymectomy or duration and severity of the disease before the operation.

Our results suggest that if anti-AChR antibodies are the principal pathogenic factor in myasthenia gravis then immunological and neurophysical variables other than the total serum anti-AChR antibody concentration contribute to the severity of the disease.

\section{Introduction}

Immunisation of animals with purified acetylcholine receptor (AChR) produces weakness and a disorder of neuromuscular transmission resembling human myasthenia gravis. ${ }^{12}$ Animals with this disorder, termed experimental autoimmune myasthenia gravis (EAMG), ${ }^{2}$ develop antibodies to AChR. Similar antibodies have been found in the sera of $87^{\circ}$ of patients with myasthenia gravis ${ }^{3}$ and bound to AChR in the muscles of both patients ${ }^{4}$ and animals ${ }^{5}$ with myasthenia gravis. Although loss of AChR from muscle ${ }^{4}{ }^{7} 7$ due to antibody-dependent mechanisms ${ }^{8-12}$ appears to be the most important factor in impairing neuromuscular transmission in myasthenia gravis and EAMG, the concentrations of antibody in the sera and the duration and severity of the disease are not closely correlated in groups of patients. ${ }^{3}$ Nevertheless, a decrease in antibody titre with a concomitant improvement in clinical state has been reported in serial studies of patients treated with plasmapheresis and immunosuppressive drugs. ${ }^{1314}$ Scadding et al ${ }^{15}$ reported that anti-AChR antibody concentrations in patients with myasthenia gravis decreased with time after thymectomy.

San Diego Veterans Administration Hospital, San Diego, California 92161

$M$ E SEYBOLD, $M D$, staff neurologist

R N BAERGEN, research assistant

Salk Institute, La Jolla, California

B NAVE, research assistant

J M LINDSTROM, PHD, associate research professor
We carried out a study of patients with myasthenia gravis in which we compared antibody concentrations in individual patients before and after thymectomy and in patients with and without thymectomy. We also analysed concentrations at various times after thymectomy and in relation to the duration of the disease.

\section{Patients, methods, and results}

All patients who took part in the study were diagnosed as having myasthenia gravis by their physician and in an independent review of their clinical history by one of us (MES). Almost all patients had a positive response to edrophonium or a decreasing response to repeated nerve stimulation, or both. Serum anti-AChR antibody titres were measured by radioimmunoassay, human $\mathrm{AChR}$ being used as the antigen. ${ }^{16}$

We studied 26 patients before and after thymectomy. Table I summarises their clinical characteristics. Variations in anti-AChR titre between successive serum samples from individual patients were noted (fig 1). Titres after thymectomy were measured from one day to

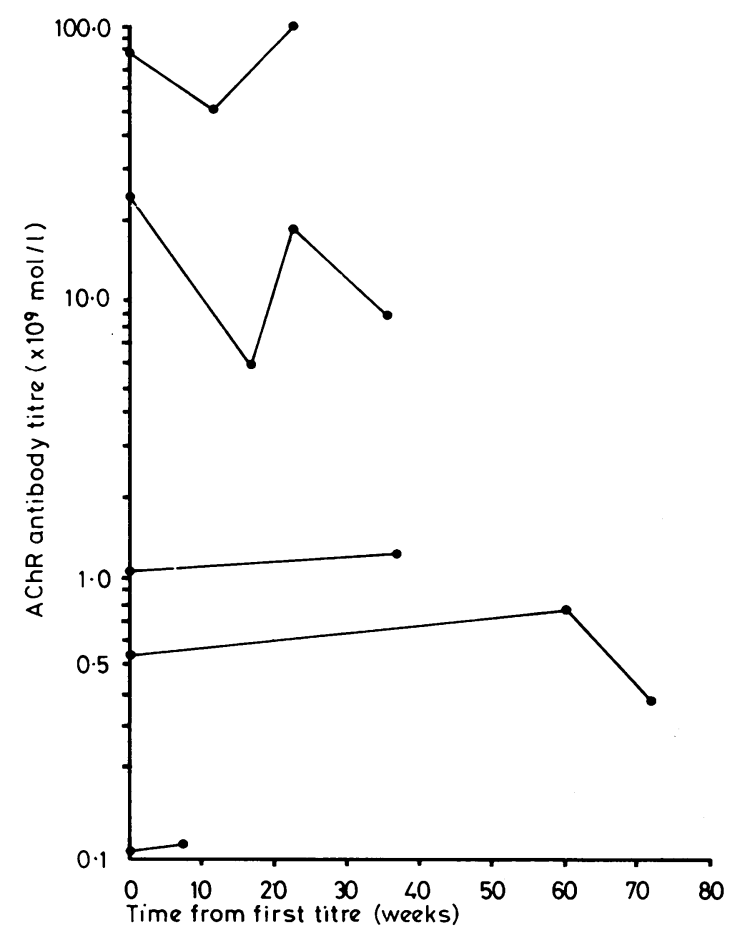

FIG 1-Serial AChR antibody titres measured before thymectomy.

TABLE I-Details of patients, duration and severity of disease, and steroid treatment. Figures are numbers of patients

\begin{tabular}{|c|c|c|c|c|c|c|c|c|c|c|c|c|c|c|c|c|c|c|}
\hline \multicolumn{2}{|c|}{ Sex } & \multicolumn{4}{|c|}{ Age (years) } & \multicolumn{4}{|c|}{ Duration of $M G$ (years) } & \multicolumn{3}{|c|}{ Steroid treatment } & \multicolumn{6}{|c|}{ Severity of $\mathrm{MG}^{*}$} \\
\hline $\mathrm{F}$ & $M$ & $\leqslant 20$ & $21-40$ & $41-60$ & $>60$ & $<1$ & $1-$ & $5-$ & 20 & None & $\begin{array}{l}\text { During } \\
\text { study }\end{array}$ & $\begin{array}{c}\text { Before } \\
\text { study only }\end{array}$ & A & 1 & $2 \mathrm{~A}$ & $2 B$ & 3 & 4 \\
\hline 19 & 7 & 7 & 12 & 4 & 3 & 4 & 21 & 1 & & 12 & 10 & 4 & 1 & 1 & 7 & 12 & 3 & 2 \\
\hline
\end{tabular}


two years nine months postoperatively (mean 17.6 weeks, median 21 days). Figure 2 shows the titres obtained before and after thymectomy. When comparison of paired observations was made with the $t$ test no significant difference was found between these titres $(t=0.858$, $\mathrm{DF}=25, \mathrm{P} \geqslant 0.05$ ). When only those titres obtained six weeks or more after thymectomy were evaluated by the $t$ test no significant change was evident $(t=0 \cdot 194, \mathrm{DF}=16, \mathrm{P} \geqslant 0 \cdot 05)$. Data correlating antibody concentration after thymectomy with clinical state were limited. Eight of the 10 patients whose postoperative state was known were improved (table II) as judged by their personal physicians. No correlation with change in antibody titre was apparent. The duration of follow-up was from two weeks to 13 months (mean 5.5 months, median 4.5 months).

Using an analysis of variance (nested (hierarchical) design) we compared 25 patients who had undergone thymectomy with 25 who had not. In all the patients titres were measured on three occasions at least one week apart (table III). Table IV lists the clinical characteristics of the two groups. If the variability shown by individual patients and within groups of patients is taken into account, there is no significant difference in antibody concentrations between patients who had and had not undergone operation $(P>0 \cdot 05)$. Nine patients who had had thymomas removed at operation had at least three titres measured at intervals of at least one week. When these patients were compared with nine without thymoma who had undergone thymectomy and nine who had not had the operation but had similar clinical characteristics no significant differences in anti-AChR antibody

TABLE II-Change in AChR antibody titre after thymectomy related to change in clinical state. Figures are numbers of patients

\begin{tabular}{l|c|c|c}
\hline \multirow{2}{*}{ Clinical state } & \multicolumn{2}{|c}{ Postoperative change in antibody titre } \\
\cline { 2 - 3 } & Increased $\geqslant 50 \%$ & Decreased $\geqslant 50 \%$ & Unchanged $(<50 \%)$ \\
\hline $\begin{array}{l}\text { Improved } \\
\text { Wnche } \\
\text { Unchanged }\end{array}$ & 3 & 1 & 4 \\
\hline
\end{tabular}

TABLE III-Comparison of titres in patients who underwent thymectomy and those who did not*

\begin{tabular}{|c|c|c|c|c|c|c|c|}
\hline \multicolumn{4}{|c|}{ Non-operated patients } & \multicolumn{4}{|c|}{ Operated patients ${ }^{\dagger}$} \\
\hline $\begin{array}{c}\text { Case } \\
\text { No }\end{array}$ & & $\begin{array}{l}\text { Titres } \\
10^{9} \mathrm{~mol} / 1\end{array}$ & & $\begin{array}{c}\text { Case } \\
\text { No }\end{array}$ & & $\begin{array}{l}\text { Titres } \\
10^{9} \mathrm{~mol} /\end{array}$ & \\
\hline \begin{tabular}{r|}
1 \\
2 \\
3 \\
4 \\
5 \\
6 \\
7 \\
8 \\
9 \\
10 \\
11 \\
12 \\
13 \\
14 \\
15 \\
16 \\
17 \\
18 \\
19 \\
20 \\
21 \\
22 \\
23 \\
24 \\
25
\end{tabular} & $\begin{array}{c}0 \cdot 222 \\
0 \cdot 258 \\
0 \cdot 299 \\
0 \cdot 520 \\
0.662 \\
1.38 \\
1.92 \\
2 \cdot 69 \\
2 \cdot 80 \\
2 \cdot 88 \\
4 \cdot 19 \\
4 \cdot 95 \\
9 \cdot 63 \\
13 \cdot 8 \\
16 \cdot 3 \\
18 \cdot 2 \\
20 \cdot 8 \\
37 \cdot 2 \\
51 \cdot 1 \\
57 \cdot 7 \\
94 \cdot 7 \\
222 \\
237 \\
254 \\
1163\end{array}$ & $\begin{array}{c}0.535 \\
0.068 \\
0.267 \\
0 \cdot 147 \\
0.573 \\
0.672 \\
3.80 \\
1.00 \\
3.14 \\
2.55 \\
3.35 \\
5.72 \\
13.2 \\
9.81 \\
9.05 \\
19 \cdot 1 \\
20.4 \\
44 \cdot 6 \\
61.6 \\
6 \cdot 22 \\
82.2 \\
99.5 \\
200 \\
251 \\
796\end{array}$ & $\begin{array}{c}0.600 \\
0.056 \\
0.247 \\
0.214 \\
0 \cdot 785 \\
0.581 \\
0.724 \\
0.188 \\
0.186 \\
2 \cdot 78 \\
3 \cdot 37 \\
5 \cdot 57 \\
13 \cdot 0 \\
9 \cdot 38 \\
7.74 \\
8 \cdot 81 \\
10 \cdot 3 \\
44 \cdot 2 \\
41.5 \\
9 \cdot 60 \\
65 \cdot 0 \\
104 \\
274 \\
263 \\
1129\end{array}$ & $\begin{array}{l}26 \\
27 \\
28 \\
29 \\
30 \\
31 \\
32 \\
33 \\
34 \\
35 \\
36 \\
37 \\
38 \\
39 \\
40 \\
41 \\
42 \\
43 \\
44 \\
45 \\
46 \\
47 \\
48 \\
49 \\
50\end{array}$ & $\begin{array}{c}0 \cdot 257 \\
0 \cdot 405 \\
1 \cdot 22 \\
7 \cdot 57 \\
8 \cdot 21 \\
13 \cdot 3 \\
14 \cdot 5 \\
21 \cdot 6 \\
26 \cdot 6 \\
28 \cdot 8 \\
31 \cdot 5 \\
39 \cdot 6 \\
40 \cdot 0 \\
41 \cdot 0 \\
46 \cdot 5 \\
48 \cdot 7 \\
51 \cdot 3 \\
53 \cdot 2 \\
62 \cdot 0 \\
97 \cdot 4 \\
98 \cdot 0 \\
112 \\
189 \\
218 \\
844\end{array}$ & $\begin{array}{c}0 \cdot 238 \\
0 \cdot 411 \\
1 \cdot 05 \\
6 \cdot 61 \\
9 \cdot 10 \\
54 \cdot 6 \\
47 \cdot 5 \\
16 \cdot 0 \\
23 \cdot 9 \\
29 \cdot 2 \\
76 \cdot 7 \\
63 \cdot 6 \\
20 \cdot 4 \\
116 \\
29 \cdot 9 \\
30 \cdot 6 \\
23 \cdot 7 \\
51 \cdot 1 \\
93 \cdot 6 \\
72 \cdot 8 \\
86 \cdot 5 \\
30.9 \\
166 \\
181 \\
585\end{array}$ & $\begin{array}{c}0 \cdot 268 \\
0 \cdot 268 \\
1 \cdot 30 \\
6 \cdot 70 \\
19 \cdot 2 \\
17 \cdot 4 \\
14 \cdot 9 \\
20 \cdot 5 \\
15 \cdot 4 \\
34 \cdot 9 \\
44 \cdot 2 \\
66 \cdot 4 \\
175 \\
90 \cdot 4 \\
50 \cdot 6 \\
29 \cdot 6 \\
11 \cdot 3 \\
66 \cdot 1 \\
91 \cdot 0 \\
146 \\
68 \cdot 9 \\
16 \cdot 3 \\
268 \\
171 \\
236\end{array}$ \\
\hline
\end{tabular}

*Each measurement separated by at least one week.

+ First titre listed was first obtained after thymectomy.

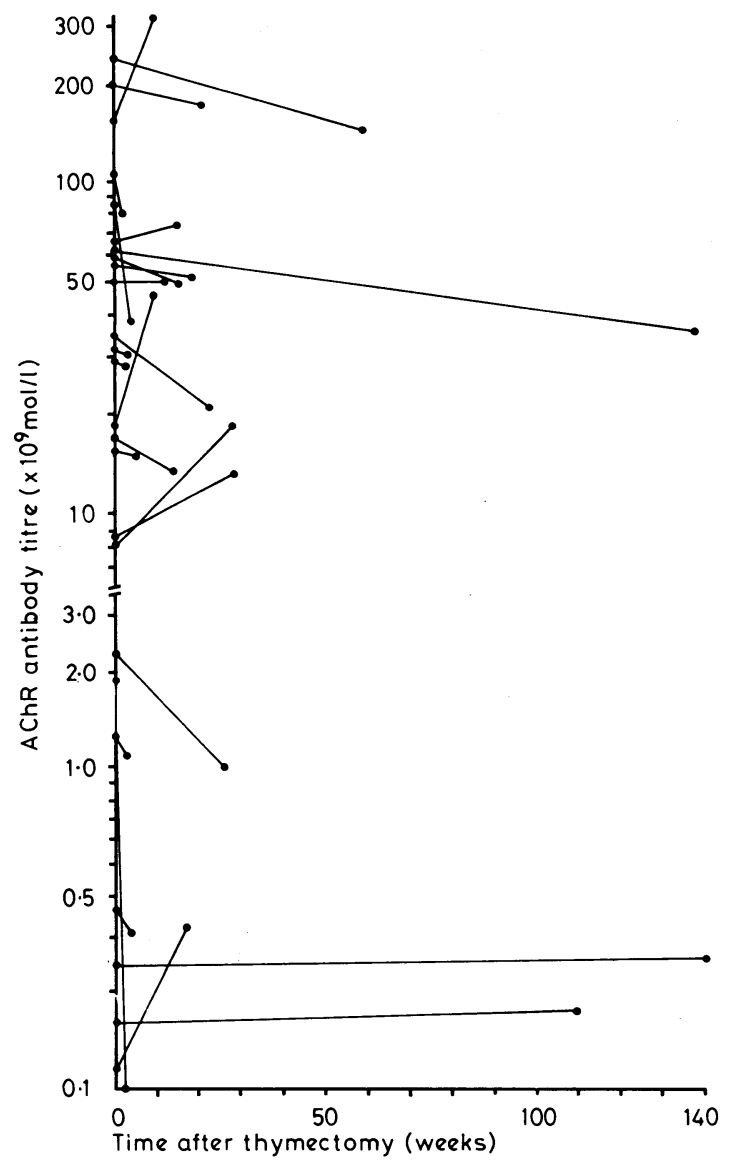

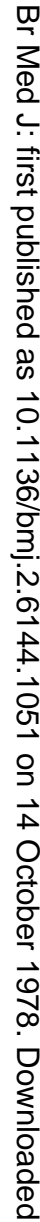

titres were found between any of the groups $(\mathbf{P}>0.05)$. Titres in both groups of patients who underwent thymectomy were obtained 3 from one day to 14 years after the operation (patients with thymoma: $\frac{}{J}$ mean 5.8 years, median 4.5 years; patients without thymoma: mean $5 \cdot 2$ years, median $2 \cdot 1$ years). Titres were obtained after thymectomy in 88 patients. The time after operation ranged from three months to 23 years (mean 6.5 years, median 5.7 years), and when several titres were available the most recent one was used in the analysis. Using the Spearman rank order correlation coefficient we found no change in 3 . titres with time after thymectomy $(t=1.0162, \mathrm{DF}=86$, correlation $=\dot{8}$ $-0 \cdot 1089)$. The same method was used to compare the titre after thymectomy with the duration of myasthenia gravis before thymectomy. No significant correlation was found $(t=0 \cdot 1589, \mathrm{DF}=85$, 을 correlation $=0 \cdot 0172$ ).

\section{Comment}

Although the role of the thymus in myasthenia gravis is uncertain, its removal is used as a treatment for the disease. Higher five- and 10-year survival and remission rates have beenc reported for patients who have undergone thymectomy than for: computer-matched patients with myasthenia gravis who have not had the operation. ${ }^{17}$ The presence of AChR-bearing muscle-like

TABLE IV-Details of patients, duration and severity of disease, and steroid treatment. Figures are numbers of patients

\begin{tabular}{|c|c|c|c|c|c|c|c|c|c|c|c|c|c|c|c|c|c|c|c|}
\hline \multirow{2}{*}{ Group } & \multicolumn{2}{|c|}{ Sex } & \multicolumn{4}{|c|}{ Age (years) } & \multicolumn{4}{|c|}{ Duration of MG (years) } & \multicolumn{3}{|c|}{ Steroid treatment } & \multicolumn{6}{|c|}{ Severity of $\mathrm{MG}^{*}$} \\
\hline & $\mathrm{F}$ & $M$ & $\leqslant 20$ & $21-40$ & $41-60$ & $>60$ & $<1$ & $1-$ & $5-$ & $\geqslant 20$ & None & $\begin{array}{l}\text { During } \\
\text { study }\end{array}$ & $\begin{array}{c}\text { Before } \\
\text { study only }\end{array}$ & A & 1 & $2 \mathrm{~A}$ & $2 \mathrm{~B}$ & 3 & \\
\hline $\begin{array}{l}\text { Operated } \\
\text { Non-operated }\end{array}$ & $\begin{array}{r}17 \\
8\end{array}$ & $\begin{array}{r}8 \\
17\end{array}$ & $\begin{array}{l}2 \\
1\end{array}$ & $\begin{array}{r}11 \\
6\end{array}$ & $\begin{array}{l}8 \\
9\end{array}$ & $\begin{array}{l}4 \\
9\end{array}$ & 6 & $\begin{array}{l}14 \\
11\end{array}$ & $\begin{array}{r}11 \\
8\end{array}$ & & 10 & $\begin{array}{l}12 \\
12\end{array}$ & $\begin{array}{l}3 \\
1\end{array}$ & 1 & 5 & $\begin{array}{r}7 \\
10\end{array}$ & $\begin{array}{l}8 \\
9\end{array}$ & $\begin{array}{l}1 \\
1\end{array}$ & 8 \\
\hline
\end{tabular}

*Modified Osserman classification: $\mathrm{A}=$ Remission. $1=$ Ocular only. $2 \mathrm{~A}=$ Mild generalised. $2 \mathrm{~B}=$ Moderately severe generalised. $3=\mathrm{Acute}$ severe. $4=\mathrm{Chronic}$ severe. 
cells in thymus culture ${ }^{18}$ has suggested that the thymus $\mathrm{AChR}$ may act as a stimulus for antibody production, which is subsequently also directed against the neuromuscular junction AChR. Alternatively, the thymus may act as the source of B-lymphocytes or of helper lymphocytes responsible for the continued production of antibody by B-lymphocytes. Culture of thymus tissue showed evidence of synthesis of AChR antibody in one of four patients with myasthenia gravis studied, and two of five patients displayed synthesis of AChR antibody by thymic lymphocytes cultured after thymectomy. ${ }^{19}$

Our failure to show a drop in serum antibody concentrations after thymectomy does not eliminate the possibility that the thymus acts as the source of either the antigen or the antibody. It implies that, by the time of thymectomy, the pathological process may be self-sustaining or the thymus may be an important source of antibody in only a few patients. Alternatively, an as yet unrecognised subpopulation of antibody may be affected by thymectomy, although total antibody concentrations may not be substantially altered.

The lack of apparent relations between serum anti-AChR antibody concentrations in patients with myasthenia gravis and thymectomy and the severity and duration of the disease suggests that if anti-AChR antibodies are the principal pathogenic factor in the disease factors other than the total serum anti-AChR concentration contribute to severity. Immunological variables might include differences in anti-AChR specificity or affinity," in anti-AChR class or subclass effecting complement fixation or antigenic modulation, or in the contribution of cellular immune mechanisms. ${ }^{21}: 2 \cdot 2$ Neurophysiological variables that might contribute to differing responses to the same concentration of serum anti-AChR antibody in different patients include differences in the initial content of $\mathrm{AChR}$ and in the ability of muscle to regenerate AChR or postsynaptic membrane structure. Identification of such immunological or neurophysiological variables would aid understanding of the pathology of myasthenia gravis.

\section{References}

1 Patrick, J, and Lindstrom, J, Science, 1973, 180, 871.

${ }^{2}$ Lennon, V, Lindstrom, J, and Seybold, M, fournal of Experimental Medicine, 1975, 144, 1365 .

${ }^{3}$ Lindstrom, J, et al, Neurology, 1976, 26, 1054.

${ }^{4}$ Lindstrom, J, and Lambert, E, Neurology, 1978, 28, 130.

${ }^{5}$ Lindstrom, J, et al, fournal of Experimental Medicine, 1976, 144, 726.

${ }^{6}$ Fambrough, D, Drachman, D B, and Satyamurti, S, Science, 1973, 182, 293.

7 Engel, A, et al, Neurology, 1977, 27, 307.

${ }^{8}$ Lennon, V, et al, fournal of Experimental Medicine, 1978, 147, 973.

${ }^{9}$ Engel, A, Lambert, E, and Howard, F, Mayo Clinic Proceedings, 1977, 52, 267.

${ }^{10}$ Heinemann, S, et al, Proceedings of the National Academy of Sciences, $1977,74,3090$.

${ }^{11}$ Appel, S, et al, Proceedings of the National Academy of Sciences, 1977, 74, 2130.

12 Kao, I, and Drachman, D B, Science, 1977, 196, 527.

${ }_{13}$ Dau, P, et al, New England fournal of Medicine, 1977, 297, 1134

14 Newson Davis, J, et al, Neurology, 1978, 28, 266.

15 Scadding, G, Thomas, H, and Havard, C, British Medical fournal, 1977, 1,1512 .

${ }^{16}$ Lindstrom, J, Clinical Immunology and Immunopathology, 1977, 7, 36.

17 Buckingham, J, et al, Annals of Surgery, 1976, 184, 453.

$18 \mathrm{Kao}, \mathrm{I}$, and Drachman, D B, Science, 1977, 195, 74

19 Vincent, A, et al, Lancet, 1978, 1, 305.

${ }^{20}$ Lindstrom, J, Campbell, M, and Nave, B, Muscle and Nerve, 1978, 1, 140.

${ }^{21}$ Abramsky, O, et al, Clinical and Experimental Immunology, 1975, 19, 11.

${ }^{22}$ Richman, D, Patrick, J, and Arnason, B, New England fournal of Medicine, 1976, 294, 694.

(Accepted 30 fune 1978)

\title{
A different kind of day hospital-for patients with preterminal cancer and chronic disease
}

\author{
E WILKES, A G O CROWTHER, C W K H GREAVES
}

British Medical fournal, 1978, 2, 1053-1056

\section{Summary and conclusions}

A new day hospital has been set up in Sheffield for patients with preterminal cancer and chronic disease. During the first 26 months 197 patients with cancer and 66 chronically sick patients attended. Of the 2701 attendances by patients with cancer, breast cancer accounted for $38 \%$. One hundred and forty of the patients with cancer died, $83 \%$ in the terminal-care unit and $12 \%$ at home. Ninety per cent of respondents to a questionnaire thought that the support provided was of great importance to both patient and family; and over two-thirds of

\footnotetext{
Department of Community Medicine, University Medical School, Sheffield S10 2RX

E WILKES, OBE, FRCP, professor of community care and general practice

A G O CROWTHER, MB, BCHIR, general practitioner and honorary lecturer

C W K H GREAVES, вM, всH, general practitioner and teacher of general practice
}

the patients were said to have benefited from improved control of symptoms.

A similar facility could be developed within existing day hospitals without major revenue consequences, and should produce a genuine improvement in care. This study suggests, however, that it would not shorten the terminal stay in hospital.

\section{Introduction}

Most day hospitals are for geriatric or psychiatric patients. We run a day hospital catering for patients with preterminal cancer and chronic disease, which has been developed (mainly through the generosity of the Nuffield Foundation) as an integral part of a terminal-care unit; and we discuss here its first 26 months.

\section{The background}

The 25-bed unit for patients with terminal cancer and the chronic sick is supported by an independent charity but most of the beds are financed by a contract with the area health authority. It takes $350-450$ patients a year, mostly suffering from disseminated cancer; some $12 \%$ of the local cancer deaths occur in the unit, the average stay being 